\title{
Forensic DNA Typing: Quo Vadis?
}

\author{
Gerhard Mertens*
}

Forensic DNA Laboratory, Antwerp University Hospital, University of Antwerp, Wilrijkstraat 10, B-2650 Edegem, Belgium

\begin{abstract}
Since Alec Jeffreys coined the term "individual-specific genetic fingerprints" in 1985, DNA typing has become indispensable in forensic analysis, having as its central rationale the evidential power of the "match" between trace evidence and suspect. Established technological advances in this field include the adoption of the polymerase chain reaction (PCR) to generate DNA profiles from minute biological samples, the use of mitochondrial DNA to obtain information from old bones and the application of Y chromosomal polymorphisms in sexual assault cases.
\end{abstract}

Present research questions focus on genetic markers for external visible traits and on improving the utility of poor quality samples with degraded DNA.

The first valid marker for a physical trait was the sex marker amelogenin, which has been part of short tandem repeat (STR) multiplex PCRs for over a decade. Current studies are investigating markers for human pigmentation, predicting hair, iris and skin colour. The relationship between genome and pigmentation however is complex, involving numerous genes. Single nucleotide polymorphisms (SNPs) in these genes make promising candidates for predictive markers.

Physical stature is also a complex genetic trait where study subjects can be phenotyped easily. Linkage analysis has revealed several short stature-quantitative trait loci, and polymorphisms in the fibrillin I gene are associated with tall stature.

An indirect approach of physical traits is inferring the geographic origin of an individual from DNA. Here, genome-wide SNP panels have been used, correctly discriminating "European", "East Asian" and "SubSahara African" ancestry, or even substructure amongst Europeans almost to the level of nationality, by typing 500000 SNPs.

The ultimate goal of this work is to achieve "molecular photofitting", using molecular techniques to construct a portrait of the person leaving a biological trace.

The other direction of contemporary forensic DNA research addresses the difficulty of obtaining a DNA profile in a degraded crime stain.

One strategy to tackle this problem uses SNPs in stead of STRs. Due to the intrinsically small size of SNPs, they are well suited for degraded samples, but there are two major drawbacks. First, due to their bi-allelic nature, the resolution of a SNP is inferior to any STR. This can be overcome by using larger numbers of SNPs, yielding the same statistical power as 10 to 15 STRs. Then, since DNA profiles in national forensic databases currently contain only a standard set of STRs, a DNA profile consisting of SNPs alone cannot be matched.

An alternative strategy would still apply STRs, but with smaller amplicons. Primer pairs are chosen closer to the repeat region, yielding shorter PCR products than with classical primers. The STRs in question are both "old", internationally used loci and newly developed systems. Thus, comparison with DNA profiles in existing forensic databases is possible.

\section{INTRODUCTION}

DNA profiling is a technique employed by forensic scientists to assist in the identification of individuals on the basis of their respective DNA profiles. It all started with the seminal work of Alec Jeffreys who coined the term "individual specific genetic fingerprints" by combining restriction

\footnotetext{
*Address correspondence to this author at the Forensic DNA Laboratory, Antwerp University Hospital, University of Antwerp, Wilrijkstraat 10, B2650 Edegem, Belgium; Tel: +31 382139 46;

E-mail: gerhard.mertens@uza.be
}

fragment length polymorphism (RFLP) analysis and multilocus probe technology [1]. Forensic application soon followed with the evidential power of the "match" between stain and suspect as its central dogma.

The next leap forward came with the introduction of the polymerase chain reaction (PCR), permitting the analysis and generation of DNA profiles from minute biological samples [2]. Autosomal short tandem repeats (STR), coamplified in multiplex-PCRs, became the cornerstone of forensic DNA testing [3], including national databases with DNA profiles of convicted felons. 
Another major breakthrough was the application of the high copy number of mitochondrial DNA [4] so that valuable information could be obtained from (very) old specimens, such as bones and teeth.

A next advance came with the introduction of $\mathrm{Y}$ chromosomal STRs [5]. In forensics, this helps the resolution of sexual assault cases, discriminating between the (female) victim's own DNA profile and the one from the assailant. This technique complements the physico-chemical separation of the female and male fraction of a vaginal fluid sample.

We will review present research and future applications of forensic DNA typing, which focuses on two domains. The first relates to the use of markers to infer, either directly or indirectly, external visible traits, while the second aims to improve the usefulness of poor quality biological samples containing degraded DNA.

\section{MOLECULAR PHOTOFITTING}

\section{Physical Traits and DNA}

Current methods for forensic DNA analysis require an identified suspect for comparison purposes. However, in those instances when there is no suspect, the crime stain's DNA profile itself provides limited information to investigators, with gender being all that can currently be deduced. Indeed, the sex marker amelogenin [6] was the first valid marker for a physical trait and has been part of all standard forensic STR multiplex PCRs for over a decade.

The physical appearance of an individual is encoded in his genome as evidenced by the striking physical similarity of identical twins. The major physical descriptors of an individual, i.e. colouring, height and facial features are highly heritable. These traits however are not caused by a single variation in the genome or even a single gene.

From the genetic point of view, physical traits are complex traits, that is multifactorial traits where several genes interacting both between themselves and with the environment define the phenotype [7].

Genetic association studies are an important tool to assess correlations between genetic variants and differences in physical traits on a population scale [8]. A major leap forward in association studies came with the discovery of millions of SNPs in the human genome sequencing projects. Now more than 11 million SNPs have been gathered into the publicly accessible SNP database (www.ncbi.nlm.nih.gov/$\mathrm{SNP} /$ ).

\section{Skin Pigmentation}

A great deal of work has focused on pigmentation, most notably skin pigmentation [9]. Here, the enzymes implicated in melanin synthesis are good contenders for genetic variation in causing diversity in pigmentation. The main candidate genes include genes for melanosome proteins (TYR, DCT, OCA2, MATP/SLC45A2), signal proteins (ASIP, $\mathrm{MC1R}$ ) and proteins involved in melanosome uptake by keratinocytes (MYO5A, RAB27A).

Pigmentation results from the production and deposition of melanin which is synthesized from tyrosine as either black/brown eumelanin or yellow/red pheomelanin. The mechanism controlling the switch from eumelanin to pheomelanin is well understood. Stimulation of the MC1R receptor results in the production of melanin. Antagonism in this interaction by the ASIP signalling protein results in decreased production of pheomelanin.

MCR1 was the first human gene identified that showed an association with normal pigment variation. There are three common MCR1 polymorphisms - R151C, R160W and D294H - which account for $90 \%$ of red hair and fair skin phenotypes.

SNPs in the ASIP gene were studied by Voisey et al. [10]. The $8818 \mathrm{~A} \rightarrow \mathrm{G}$ SNP was found at higher frequency in Africans as compared with other populations. Within the European population, a strong association was observed between the $\mathrm{G}$ allele and dark hair colour. In the MATP gene (recently renamed SLC45A2), two SNPs - Phe374Leu and Glu272Lys - are significantly associated with pigmentation. The 374Leu allele is more common in non-Caucasian populations, while - compared to Europeans - an increase frequency of the 272Lys allele is observed in Asian and African populations. Within the European populations, these polymorphisms showed highly significant associations with dark hair, skin and eye pigmentation.

The genetic basis of normal human pigmentation variation is decipherable and future forensic DNA tools will provide predictive investigation to crime scene officers [11].

Zaumsegel et al. [12] selected a set of 11 SNPs based on their relevance for human pigmentation and located in the OCA2 and MATP (SLC45A2) gene. 87 Germans and 71 Sub-Sahara Africans were genotyped for these SNPs by multiplex-PCR followed by SNaP shot. The two sample populations were chosen because of their clear difference in skin pigmentation. Five of the 11 SNPs proved informative, showing clearly different allele frequencies between both populations. Thus these five SNP can be considered pigmentation informative as well as ancestry informative, while the other six SNPs may have other effects which cannot be detected in the two groups studied.

Myles et al. [13] measured allele frequencies in Europeans, Chinese and Africans for 24 pigmentation genes from two large-scale SNP data sets. This revealed patterns of widely contrasting frequency differences between the populations. Notably the DCT gene was strongly associated with pigmentation control in Asians. The ASIP and OCA2 genes appeared to play important roles in pigmentation patterns of Europeans and Asians, while the MATP (SLC45A2) and TYR genes affect pigmentation only in Europeans [14].

\section{Eye Colour}

Iris pigmentation is related to skin pigmentation and is a major element in the facial features characterizing an individual. More than $70 \%$ of eye colour variation is due to quantitative trait loci (QTL) localised on chromosome 15q [15], where the OCA2 gene is localised. OCA2 is a transporter for tyrosine, an essential substrate in the production of melanin, determining the pigmentation phenotype. Branicki et al. [16] genotyped 390 Polish for 11 SNPs in the OCA2 gene, by multiplex PCR followed by SNaP shot. Based on conventional statistics and an evolutionary method known as 
"tree scanning", it was found that exonic position rs 1800407 (Arg419Gln) is most significantly associated with iris colour.

\section{Was he Tall or Short?}

From a genetic point of view, adult height is a complex trait with high heritability and the possibility to phenotype study subjects by easy and accurate measurement. Still, studies of stature as a quantitative complex trait are less advanced than studies of pigmentation.

Several short stature-QTLs have been identified through genome-wide linkage analysis [17]: STQL1 on chromosome 6, STQL2 on chromosome 7, STQL3 on chromosome 12, STQL4 on chromosome 13, STQL5 on chromosome 3, STQL6 on chromosome X, STQL7 on chromosome 1 and STQL8 on chromosome 9.

Polymorphisms in the fibrillin I gene are associated with tall stature in normal individuals [18].

This research has not yet resulted in an assay that can be applied in the forensic setting.

\section{Continuous Facial Morphology}

A search of literature has not revealed any published work on the variation of continuous facial features in man. Some characteristics are anticipated to be monogenic, following Mendelian inheritance. These include chin dimple, facial dimples, hairy ears, earlobe attachment and freckles. The genes for these traits, nor associated SNPs, have yet been located.

\section{Legal Implications}

The concept of generating a physical description of an individual from the analysis of his or her DNA has been coined "Molecular Photofitting" [19]. While much is expected from this strategy, it will also require adaptation of the legislation on forensic DNA analysis in many countries. In most countries, only non-coding DNA can legally be applied in forensic examination and DNA based prediction of physical traits might be considered a violation of privacy. Actually, the Netherlands is the only country that has legally permitted the use of the molecular photofitting concept in criminal investigation [20].

\section{ANCESTRY-INFORMATIVE MARKERS}

\section{Predicting Geographic Origin from DNA}

Recently, it has been demonstrated that an individual's geographic ancestries can be inferred from genetic markers, called ancestry-informative markers (AIM). In forensics, the prediction of geographic origin from body fluids recovered from a crime scene may provide meaningful information for investigators. It might narrow the pool of suspects, could be instrumental when eye witnesses are unavailable and could help for identification of corpses.

Y-chromosome loci and mitochondrial DNA variation [21] are haploid, uniparental inherited markers which are very interesting for population genetic studies, but can provide conflicting results within admixed populations. Autosomal markers reflect both paternal and maternal heritage and are therefore more suited for the prediction of geographic origin. Autosomal microsatellites do not exhibit large enough contrasts in allele frequencies between popula- tions to be useful in numbers below 50 loci, mainly due to their mutational instability [22]. Autosomal SNPs have emerged as the best AIM due to their low mutation rate, density of distribution across the genome and full range of allele frequency patterns among populations [23].

Since the majority of human worldwide genetic diversity takes the form of geographic clines [24], it is essential to find the small number of SNPs that show the most pronounced allele frequency discontinuities between continental regions to create sets with population "diagnostic" genotypes.

In clinical genetics, AIMs are an increasing part of genetic association studies but have not been fully developed into a practical forensic test. The following examples illustrate current advances in this area.

\section{Resolution of SNPs}

Phillips et al. [25] developed a single tube 34-plex SNP assay for assignment of ancestral origin by selecting AIMs exhibiting highly contrasting allele frequency distributions between European, Sub-Sahara African and East Asian population groups. They developed a classification algorithm based on maximum likelihood using a database of 360 individuals, sampled from two populations each from the major population groups (60 Spanish and 60 Danish for the European metapopulation, 60 Mozambican and 60 Somali for the Sub-Sahara African metapopulation, 60 Chinese and 60 Taiwanese for the East Asian metapopulation). The performance of the ancestry predictive algorithm was tested using Centre d'Étude du Polymorhisme Humain (CEPH)-Human Genome Diversity panel samples from 520 individuals with known geographic ancestry (160 Europeans, 123 Sub-Sahara Africans, 237 East Asians). Only 5 of these samples were erroneously assigned, comprising two Europeans as "African" and three Europeans as "East Asian", resulting in a practical error rate of $1 \%$. The incorrectly classified individuals were not a random set but came from Sardinia (4 individuals) and from the Adygei population of the WestCaucasus (1 individual). Sardinia is a well-known genetic outlier in Europe and the Adygei live on the extreme eastern edge of the continent.

32 SNPs were selected by Chrystelle et al. [26] because of their allele frequency differences between the three major population groups: Sub-Sahara African, East Asian and European. The selected SNPs were genotyped using TaqMan technology on individuals from the three metapopulations (115 from each metapopulation) and also from two geographically intermediate groups (115 from North Africa and 155 from Sub-Continental Asia). The geographic affiliation of the samples was inferred using the clustering algorithm implemented in the STRUCTURE program. This analysis showed that individuals can be grouped into three genetic clusters $(K=3)$ which are strictly correlated with the three continental regions. The same accuracy of assignment was observed by using the nine loci with the highest genetic distance (measured as $\mathrm{F}_{\mathrm{ST}}$ ). The assumption of five genetic clusters $(K=5)$ allowed the distinction of North Africans and South Asians, but here the use of the whole panel of 32 SNPs is recommended to avoid false assignment.

16 SNPs were selected by Daniel et al. [27] to distinguish the major populations residing in present day Australia. They recorded geographical ancestry over three generations as 
well as eye and hair colour information for 242 Australians, comprising 51 East Asians, 33 Sub-Continental Asians, 25 Middle-Easterns, 79 Europeans, 20 North Africans and 34 Sub-Sahara Africans. The individuals were genotyped by PCR followed by SNaP Shot technology. Population assignment was assessed using likelihood algorithms applied through the GenAlEx software package. This removes the individual sample from the dataset before it is assigned to a population. Using the $16 \mathrm{SNP}$ set, a high degree of accuracy was achieved for the inference of Sub-Sahara African (100\%), European (91\%) and North African (90\%) ancestry; while an intermediate degree of accuracy was observed for Sub-Continental Asian (79\%) and Middle-Eastern (60\%) origin. One of the16 SNPs, Leu374Phe, is located in the MATP (SLC45A2) gene which is a major determinant of pigmentation. As a crude classification of pigmentation, study subjects were classified into three groups: "dark", "medium" and "light". Using the GenAlEx assignment technique, a correct inference of the phenotype was obtained in $91 \%$ of the "dark" and $98 \%$ of the "light". Given the polygenic nature of pigmentation, Leu374Phe should be used in combination with other pigmentation-associated SNPs to make even more reliable phenotypic deductions.

While it thus has been proven that the major continental population groups can be differentiated using genetic markers, the question remains whether any reproducible substructure can be demonstrated within the European metapopulation. The question has been addressed in the setting of disease association studies where the association is tested between genetic markers and polygenic or complex diseases, such as rheumatoid arthritis or diabetes. Indeed, differences in population genetic structure between disease cases and controls can lead to false positive associations [28]. Since many studies focus on patients from European descent, the potential impact of European substructure on association testing has specifically engendered interest [29].

\section{Array Technology for Increasing Detail}

To assess the informativeness for within-European ancestry, Price et al. [30] used the 500K Affymetrix GeneChip or the Illumina HumanHap bead array to genotype 583 SNPs on 667 samples from 7 European countries: 180 Swedish, 82 UK, 60 Polish, 60 Spanish, 124 Italian, 80 Greek and 81 US Ashkenazi Jewish. Principal component analysis clearly separated the samples into three clusters, corresponding to northwest European, southeast European and Ashkenazi Jewish ancestry. From these 583 SNPs, they then selected a subset of 300. Rerunning principal component analysis on the same samples using only these SNPs yielded the same results as before. So, these 300 SNPs can be considered an informative marker set distinguishing ancestries within Europe.

In a similar way, Seldin et al. [31] typed 928 individuals with European ancestry (Swedish, English, Irish, German, Ukrainian, Italian, Spanish, Portuguese and Greek) for 2657 SNPs using the Illumina bead array. Using the programme STRUCTURE, the samples were examined under different assumptions of the number of clusters, ranging from one to ten $(\mathrm{K}=1, \ldots \mathrm{K}=10)$. The data significantly favoured the assumption of $K=2$, i.e. the distinction of two clusters. The analysis showed consistent assignment of the Italian, Span- ish, Portuguese and Greek samples to the same cluster, while clustering the Swedish, English, Irish, German and Ukrainian samples in the other group. Thus, the 2657 SNPs consistently made the distinction between the "northern" and "southern" European population groups.

Lao et al. [32] used the $500 \mathrm{~K}$ GeneChip array to type 500 568 SNPs in 2514 individuals from 23 sampling sites located in one of 20 different European countries. These comprehensive SNP genotype data from 23 European subpopulations provided a dense coverage at both the geographic and genomic level and represents the largest Europe-wide genetic study to date. It allowed for principal component analysis and to describe the genetic structure of the European metapopulation with the highest resolution. It could be concluded that although the amount of differentiation within the European autosomal gene pool is small, the existing genetic differences correlate well with geographic distances. The authors were the first to show that inferring geographic origin of an unknown person from autosomal DNA markers is feasible down to the level of Europeans sub-regions.

\section{MINI-STRS}

\section{The Problem of DNA Degradration}

It is common to encounter highly degraded DNA samples in a criminal investigation. The DNA may be so degraded that normal PCR amplification gives inconclusive results. The degradation processes affect the typing results in different ways: nucleases or oxidative damage affects the DNA structure itself, while indirectly co-extracted agents may inhibit the PCR reaction. The extent of the degradation process depends on two factors: time and environmental conditions. Degradative processes accumulate with time while environmental conditions (temperature, humidity, $\mathrm{pH}$, soil chemistry) modify the rate and aggressiveness of degradation [33]. Short amplicon approaches have recently been developed for the analysis of degraded DNA.

One way to improve the success rate for degraded DNA is to utilize redesigned STR primers, with the primers located closer to the repeat region, thus generating shorter amplicons. For these assays, the designation "mini-STR" was introduced in 2003 [34].

\section{Development of a Mini-STR Multiplex}

Camacho et al. [35] constructed a mini-SGM multiplex which encompasses TH01, FGA, D18S51, D16S539 and D2S1338, which are common STR markers in human identity testing. Using this method, a full DNA profile was obtained in two cases where the standard STR multiplex Powerplex 16 (Promega) showed drop-out of alleles greater than $300 \mathrm{bp}$ (tissue preserved in a paraffin block) or gave no results at all (bone of corpse immersed in lake water for 15 months).

Another example of a homemade mini-STR comes from Decorte et al. [36]. They developed a multiplex comprising amelogenin, four conventional STRs (TH01, D18S51, D21S11, FGA) with reduced amplicon size and four "new" mini-STRs (D1S1677, D2S441, D10S1248, D22S1045). The method was applied to a panel of 198 Belgians typed with Powerplex 16 (Promega). Full concordance was found for the common loci TH01, D18S51 and D21S11. A sensitivity 
study on a serial dilution of DNA samples under the standard conditions of 30 PCR cycles showed the occurrence of allele or locus dropout when the DNA input was less than $100 \mathrm{pg}$ of DNA. However, by increasing the number of cycles to 34 , a reproducible DNA profile was obtained when the amount of DNA was decreased to $30 \mathrm{pg}$. The sensitivity was two- to fourfold higher than the commercial standard STR multiplex PCRs SGM Plus (Applied Biosystems) and Powerplex 16 (Promega).

Not surprisingly, commercial suppliers have not stayed behind in the development of mini-STR multiplexes. An example is found in the Minifiler [37] from Applied Biosystems. This is a 9-plex mini-STR amplification kit, including the sex determining marker amelogenin and the most common problematic loci (above $200 \mathrm{bp}$ ) of the Identifiler kit (Applied Biosystems): FGA, D21S11, D18S51, D13S317, D7S820, D16S539, CSF1PO and D2S1338. Minifiler allowed to complete partial Identifiler profiles in 16 compromised samples (blood, saliva, tooth, bone and hair) in a study by Andrade et al. [38].

\section{SNPS}

\section{International Consortia and the Advantages of SNPs}

Research projects such as the SNP Consortium [39] and the International HapMap Consortium [40] identified millions of SNPs throughout the human genome and set up public databases allowing easy access to a huge amount of data. In a forensic context there is great interest in SNPs because of their abundance in the genome, low mutation rates and possibility of analysis in short amplicons improving successful amplification of degraded DNA.

The advantages of SNPs for forensic analysis include: small amplicon size, working better on degraded samples; lower mutation rate compared with STRs $\left(10^{-8}\right.$ vs. $\left.10^{-3}\right)$; amenablity to high throughput; abundance in the human genome; provision of specific information (individual identification, ancestry, lineage or phenotype).

There are also a number of limitations or challenges to be summed up: no commercial kits are available at present; there are no widely established core loci; mixture resolution issues exist; large multiplex assays are required; and SNPs are not likely to replace STRs in national DNA databases.

In their conclusion, a panel of experts agreed while SNPs would not replace STRs for most forensic applications anytime soon, SNP markers and assays should continue to be explored. SNPs may serve as an adjunct to STRs for solving special problems in forensic genetics [41].

\section{Forensic Application}

The SNPforID consortium (www.snpforid.org) was established with support from the European Union with the aim of developing a SNP assay for forensic use [42]. A major achievement of this enterprise was the selection of 52 SNPs and their incorporation into a single multiplex PCR with amplicons ranging in size from 59 to $115 \mathrm{bp}$ [43]. The analysis method of choice within the consortium was SNaPshot (Applied Biosystems). An example of a population genetic study using the SNPforID 52-plex assay can be found in the work of Pereira et al. [44]. In the Portuguese popula- tion, they obtained a random match probability of $2.6 \times 10^{-20}$, demonstrating the forensic informativeness of the 52 SNPs.

The SNPforID 52-plex also proved successful at analyzing degraded DNA, but there were problems with high background noise that could lead to incorrect allele calls. To tackle this problem, the SNPforID Consortium developed the Genplex technology [45]. This was done through modification of the SNPlex system (Applied Biosystems) and utilising oligo-ligation of PCR products followed by probe hybridisation to generate dye-labelled, allele-specific oligonucleotides which are detected by capillary electrophoresis. Genplex technology was used to type 48 SNPs plus amelogenin. The chosen SNPs provide match probabilities of $9.6 \mathrm{x}$ $10^{-18}$ for Europeans and $6.9 \times 10^{-16}$ for Africans. The success rate of Genplex was tested by typing $55 \mathrm{UV}$ and naturally degraded tissue, bone and teeth samples in three laboratories. The samples were also examined with the standard PCR STR multiplexes Powerplex 16 (Promega) and SGMPlus (Applied Biosystems). It was shown that the Genplex technique provides a higher success rate than STR-based methods when typing degraded DNA.

Fondevilla et al. [46] compared the performance of established and novel genotyping methods in 15 skeletal samples found in the moist and acid soil of North West Spain. DNA extracts were quantified by real-time PCR, using the Quantifiler kit (Applied Biosystems), which includes an internal positive control to detect the presence of PCR inhibitors. Standard PCR typing was represented by the Identifiler (Applied Biosystems) and Powerplex 16 (Promega) kits. Two mini-STRs were tested: MiniNC01 (developed at NIST) and Minifiler (Applied Biosystems). SNP typing comprised two assays: the SNPforID 52-plex human identification set and the SNPforID 34-plex ancestry informative set.

This comparative study showed that simple dilution of the DNA extract enhanced the genotyping success in 13 of the 15 samples, suggesting that inhibitors play a critical role in reducing PCR efficiency in severely degraded samples. Still, the long amplicon systems Powerplex 16 and Identifiler, appeared to be more affected by inhibitors. In contrast, SNP typing showed relative immunity from PCR inhibition. If amplicon length is an important factor with or without inhibition control, then the success rate should be expected to rise as amplicon size diminishes. This was indeed observed with the standard amplicon STRs, Powerplex 16 showing the highest overall failure rate. This trend continued as the degree of degradation rose, and longer Indentifiler loci failed to amplify (amplicons up to $380 \mathrm{bp}$ ), followed by Minifiler (amplicons up to $300 \mathrm{bp}$ ). The performance of mini-STR loci with amplicons of 100 to $300 \mathrm{bp}$ did not differ markedly, however PCR products below $100 \mathrm{bp}$, notably those of MiniNC01 (all amplicons < $120 \mathrm{bp}$ ) were resistant to even the most aggressive degradation in the examined samples. The authors concluded that for most samples, standard STR typing methods will suffice if inhibition is properly assessed and controlled prior to PCR. A further level of degradation, characterised by extremely aggressive environmental conditions over long periods of time can present the most challenging analyses. This appeared in the analysis of two femurs, one from a 35-year internment in a tomb, the other being buried in forest soil for 10 years. High molecular weight DNA was absent from these samples and all standard 
STRs failed, together with most mini-STR loci. In contrast, successful amplification of the shortest amplicon mini-STRs and all SNP multiplexes indicated that short, fragmented DNA was present was present in sufficient quantity for efficient PCR of these systems.

Thus, an optimal analysis method for degraded DNA can be chosen between standard STRs and short-amplicon STRs combined with SNP typing.

\section{"NEW" STRs}

\section{European Strategies for the Future}

In 2005 the ENFSI and EDNAP groups came forward with a number of recommendations for new European STR loci [47]:

$1^{\circ}$ Adopt mini-STRS to increase robustness and sensitivity of forensic DNA analysis.

$2^{\circ}$ The prime utilisation of SNPs will be in relation to mass disasters dealing with highly compromised samples, but can be carried out independent of national DNA databases.

$3^{\circ}$ Retain existing core-loci used in national DNA databases and convert into mini-STRs by re-engineering with primers built close to the repeat region.

$4^{\circ}$ Install the mini-STRs D10S1248, D14S1434 and D22S1045 as new core-loci.

$5^{\circ}$ A secondary list of loci (D12S391, D1S656, TPOX) can be considered by manufacturers to convert into useful mini-STRs.

$6^{\circ} \mathrm{A}$ balance should be struck between the size of a PCR multiplex and its sensitivity.

Following up on these recommendations, two differing but parallel strategies have emerged [48]. The first employs a 13 STR multiplex incorporating 3 mini-STRs (D10S1248, D22S1045, D2S441) into the current multiplex test. The second strategy employs a multiplex of 6 high molecular weight STRs (in current use) modified to provide smaller amplicons, combined with two additional loci of high discriminating power (D1S1656, D12S391). Eventually, the two strategies will converge to provide a single multiplex of 15 STRs.

\section{United States Initiatives}

Also in the United States, the National Institute of Standards and Technology (NIST) is characterising additional STR loci with a number of potential uses, such as forensic DNA casework, but also missing persons/mass disaster sample testing and complex paternity testing. NIST have set out to find loci with narrow allele ranges, moderate to high heterozygosities and clean flanking sequences that can be used in mini-STR assays.

A first set of new mini-STRs developed by NIST are the loci D10S1248, D14S1434, D22S1045 which can be coamplified in a multiplex PCR named NC01 [49]. Population genetic studies, such as the one of Onofri et al. [50] have been performed, yielding population specific allele frequencies and showing the power of discrimination and other forensic parameters to be similar to that of the nine loci of Profiler Plus (Applied Biosystems), a standard STR multiplex.
D1S1677, D2S441 and D4S2364 constitute a second set of new mini-STRs developed at NIST, to be amplified in a multiplex PCR named NC02. A population genetic study in North-Western Italians by Peloso et al. [51] showed that these mini-STRs, combined with the NC01 triplex, have a power of discrimination of 0.9999 .

Finally, a comprehensive multiplex assay has been developed, capable of amplifying 22 new autosomal STRs (D6S474, D12ATA63, D22S1045, D10S1248, D1S1677, D11S4463, D4S2364, D9S1122, D2S1776, D10S1435, D3S3053, D5S2500, D1S1627, D3S4529, D2S441, D6S1017, D4S2408, D171301, D1GATA113, D18S853, D20S482, D14S1434) and the amelogenin locus [52]. This 23-plex dubbed "Autoplex" uses five-dye chemistry to keep all PCR products below $400 \mathrm{bp}$ in size. Three of these STRs - D10S1248, D2S441 and D22S1045 - have been recommended for extending the core European loci.

\section{CONCLUSION}

Over the past 20 years, DNA technology has truly revolutionised forensic science. Future developments will focus on the physical description of an individual from biological traces at a crime scene by the use of not only minute, but also degraded stain material. It seems only budgetary restraints and the inertia of international legal change may limit the tempo at which these developments come into daily practice.

\section{REFERENCES}

[1] Jeffreys, A.J.; Wilson, V.; Thein, S.L. Individual-specific 'fingerprints' of human DNA. Nature, 1985, 316, 76-79.

[2] Kimpton, C.P.; Gill, P.; Walton, A.; Urquhart, A.; Millican, E.S.; Adams, M. Automated DNA profiling employing multiplex amplification of short tandem repeat loci. PCR Methods Appl., 1993, 3, 13-22.

[3] Gill, P.; Brinkmann, B.; d'Aloja, E.; Andersen, J.; Bar, W.; Carracedo, A.; Dupuy, B.; Eriksen, B.; Jangblad, M.; Johnsson, V.; Kloosterman, A.D.; Lincoln, P.; Morling, N.; Rand, S.; Sabatier, M.; Scheithauer, R.; Schneider, P.; Vide, M.C. Considerations from the European DNA profiling group (EDNAP) concerning STR nomenclature. Forensic Sci. Int., 1997, 87, 185-192.

[4] Butler, J.M.; Levin, B.C. Forensic applications of mitochondrial DNA. Trends Biotechnol., 1998, 6, 158-162.

[5] Jobling, M.A.; Pandya, A.; Tyler-Smith, C. The Y chromosome in forensic analysis and paternity testing. Int. J. Legal Med., 1997, 110, 118-124.

[6] Pouchkarev, V.P.; Shved, E.F.; Novikov, P.I. Sex determination of forensic samples by polymerase chain reaction of the amelogenin gene and analysis by capillary electrophoresis with polymer matrix. Electrophoresis, 1998, 19, 76-79.

[7] Glazier, A.M.; Nadeau, J.H.; Aitman, T.J. Finding genes that underlie complex traits. Science 2002, 298, 2345-2349.

[8] Risch, N.; Merikangas, K. The future of genetic studies of complex human diseases. Science, 1996, 273, 1516-1517.

[9] McEvoy, B.; Beleza, S.; Shriver, M.D. The genetic architecture of normal variation in human pigmentation, an evolutionary perspective and model. Hum. Mol. Genet., 2006, 15, R176-R181.

[10] Voisey, J.; Box, N.F.; van Daal, A. A polymorphism study of the human Agouti gene and its association with MC1R. Pigment Cell. Res., 2001, 14, 264-267.

[11] van Daal, A. The genetic basis of human pigmentation. FSI Genet Suppl. Ser. 1, 2008, 541-543.

[12] Zaumsegel, D; Rotschild, M.; Schneider, P. SNPs for the analysis of pigmentation genes - a comparative study. FSI Genet. Suppl. Ser. 1, 2008, 544-546.

[13] Myles, S.; Somel, M.; Tang, K.; Kelso, J.; Stoneking, M. Identifying genes underlying skin pigmentation differences among human populations. Hum. Genet., 2007, 120, 613-621. 
[14] Norton, H.L.; Kittles, R.A.; Parra, E.; McKeigue, P.; Mao, X.; Cheng, K.; Canfield; V.A.; Bradley, D.G.; McEvoy, B.; Shriver, M.D. Genetic evidence for the convergent evolution of light skin in Europeans and East Asians. Mol. Biol. Evol., 2007, 24, 710-722.

[15] Zhu, G.; Evans, D.M.; Duffy, D.L.; Montgomery, G.W.; Medland, S.E.; Gillespie, N.A.; Ewen, K.R.; Jewell, M.; Liew, Y.W.; Hayward, N.K.; Sturm, R.A.; Trent, J.M.; Martin, N.G. A genome scan for eye color in 502 twin families: most variation is due to a QTL on chromosome 15q. Twin Res., 2004, 7, 197-210.

[16] Branicki, W.; Szcerbinska, A.; Brudnik, U.; Wolanska-Nowak, P.; Kupiec, T. The OCA2 gene as a marker for eye colour prediction. FSI Genet. Suppl. Ser. 1, 2008, 536-537.

[17] Hirschhorn, J.N.; Lindgren, C.M.; Daly, M.J.; Kirby, A.; Schaffner, S.F.; Burtt, N.P.; Altshuler, D.; Parker, A.; Rioux, J.D.; Platko, J.; Gaudet, D.; Hudson, T.J.; Groop, L.C.; Lander, E.S. Genomewide linkage analysis of stature in multiple populations reveals several regions with evidence of linkage to adult height. Am. J. Hum. Genet., 2001, 69, 106-116.

[18] Mamada, M.; Yorifuji, T.; Yorifuji, J.; Kurokawa, K.; Kawai, M.; Momoi, T.; Nakahata, T. Fibrillin I gene polymorphism is associated with tall stature of normal individuals. Hum. Genet., 2007, 120,733-735.

[19] Frudakis, T. Molecular Photofitting: Predicting Ancestry and Phenotype Using DNA. Burlington MA: Academic Press, 2008.

[20] Ossorio, P.N. About face: forensic genetic testing for race and visible traits. J. Law Med. Ethics, 2006, 34, 277-292.

[21] Jorde, L.B.; Watkins, W.S.; Bamshad, M.J.; Dixon, M.E.; Ricker, C.E.; Seielstad, M.T.; Batzer, M.A. The distribution of human genetic diversity: a comparison of mitochondrial, autosomal, and Ychromosome data. Am. J. Hum. Genet., 2000, 66, 979-988.

[22] Lowe, A.L.; Urquhart, A.; Foreman, L.A.; Evett, I.W. Inferring ethnic origin by means of an STR profile. Forensic Sci. Int., 2001, $119,17-22$.

[23] Rosenberg, N.A.; Li, L.M.; Ward, R.; Pritchard, J.K. Informativeness of genetic markers for inference of ancestry. Am. J. Hum. Genet., 2003, 73, 1402-1422.

[24] Rosenberg, N.A.; Mahajan, S.; Ramachandran, S.; Zhao, C.; Pritchard, J.K.; Feldman, M.W. Clines, clusters, and the effect of study design on the inference of human population structure. PLoS Genet., 2005, 1, e70.

[25] Phillips, C.; Sanchez, J.J.; Fondevilla, M.; Gomez-Tato, A.; Alvarez-Dios, J.; Calaza, M.; Caseres de Cal, M.; Ballard, D.; Lereu, M.V.; Carracedo, A. Inferring ancestral origin using a single multiplex assay of ancestry-informative marker SNPs. FSI Genet., 2007, 1,273-280.

[26] Chystelle, R.; Christelie, B.; Poisan, J.P. New set of markers for individual geographic origin. FSI Genet. Suppl. Ser. 1, 2008, 482483.

[27] Daniel, R.; Sanchez, J.J.; Nassif, N.T.; Hernandez, A.; Walsh, S.J. SNPs associated with physical traits: a valuable tool for the inference of biogeographical ancestry. FSI Genet. Suppl. Ser. 1, 2008, 538-540.

[28] Marchini, J.; Cardon, L.R.; Phillips, M.S.; Donnelly, P. The effects of human population structure on large genetic association studies. Nat. Genet., 2004, 36, 512-517.

[29] Bauchet, M.; McEvoy, B.; Pearson, L.N.; Quillen, E.E.; Sarkisian, T.; Hovhannesyan, K.; Deka, R.; Bradley, D.G.; Shriver, M.D. Measuring European population stratification with microarray genotype data. Am. J. Hum. Genet., 2007, 80, 948-956.

[30] Price, A.L.; Butler, J.; Patterson, N.; Capelli, C.; Pascali, V.L.; Scarnicci, F.; Ruiz-Linares, A.; Groop, L.; Saetta, A.A.; Korkolopoulou, P.; Seligsohn, U.; Waliszewska, A.; Schirmer, C.; Ardlie, K.; Ramos, A.; Nemesh, J.; Arbeitman, L.; Goldstein, D.B.; Reich, D.; Hirschhorn, J.N. Discerning the ancestry of European Americans in genetic association studies. PLoS Genet., 2008, 4, e236.

[31] Seldin, M.F.; Shigeta, R.; Villoslada, P.; Selmi, C.; Tuomilehto, J.; Silva, G.; Belmont, J.W.; Klareskog, L.; Gregersen, P.K. European population substructure: clustering of northern and southern populations. PLoS Genet., 2006, 2, e143.

[32] Lao, O.; Lu, T.T.; Nothnagel, M.; Junge, O.; Freitag-Wolf, S.; Caliebe, A.; Balascakova, M.; Bertranpetit, J.; Bindoff, L.A.; Comas, D.; Holmlund, G.; Kouvatsi, A.; Macek, M.; Mollet, I.; Parson, W.; Palo, J.; Ploski, R.; Sajantila, A.; Tagliabracci, A.; Gether, U.; Werge, T.; Rivadeneira, F.; Hofman, A.; Uitterlinden, A.G.; Gieger, C.; Wichmann, H.E.; Rüther, A.; Schreiber, S.;
Becker, C.; Nürnberg, P.; Nelson, M.R.; Krawczak, M.; Kayser, M. Correlation between genetic and geographic structure in Europe. Curr. Biol. 2008, 18, 1241-1248.

[33] Burger, J.; Hummel, S.; Hermann, B.; Henke, W. DNA preservation: a microsatellite-DNA study on ancient skeletal remains. Electrophoresis, 1999, 20, 1722-1728.

[34] Butler, J.M.; Shen, Y.; McCord, B.R. The development of reduced size STR amplicons as tools for analysis of degraded DNA. J. Forensic Sci., 2003, 48, 1054-1064.

[35] Camacho, S.; Vieira-Silva, C.; Dario, P.; Ribeiro, T.; Espinheira, R.; Geada, H. Mini-SGM multiplex in degraded samples. FSI Genet. Suppl. Ser. 1, 2008, 100-101.

[36] Decorte, R.; Liu, C.F.; Vanderheyden, N.; Cassiman, J.J. Development of a novel miniSTR multiplex assay for typing degraded DNA samples. FSI Genet. Suppl. Ser. 1, 2008, 112-114.

[37] Mulero, J.J.; Chang, C.W.; Lagacé, R.E.; Wang, D.Y.; Bas, J.L.; McMahon, T.P.; Hennessy, L.K. Development and validation of the AmpFISTR MiniFiler PCR Amplification Kit: a MiniSTR multiplex for the analysis of degraded and/or PCR inhibited DNA. $J$. Forensic Sci., 2008, 53, 838-852.

[38] Andrade, L.; Bento, A.M.; Serra, A.; Carvalho, M.; Gamero, J.J.; Oliveira, C.; Batista, L.; Lopes, V.; Balsa, F.; Corte-Real, F.; Anjos, M.J. AmplFISTR Minifiler PCR amplification kit: the new miniSTR multiplex kit. FSI Genet. Suppl. Ser. 1, 2008, 89-91.

[39] Thorisson, G.A.; Stein, L.D. The SNP Consortium website, past, present and future. Nucleic Acids Res., 2003, 31, 124-127.

[40] International HapMap Consortium, Frazer, K.A.; Ballinger, D.G.; Cox, D.R.; Hinds, D.A.; Stuve, L.L.; Gibbs, R.A.; Belmont, J.W.; Boudreau, A.; Hardenbol, P.; Leal, S.M.; Pasternak, S.; Wheeler, D.A.; Willis, T.D.; Yu, F.; Yang, H.; Zeng, C.; Gao, Y.; Hu, H.; Hu, W.; Li, C.; Lin, W.; Liu, S.; Pan, H.; Tang, X.; Wang, J.; Wang, W.; Yu, J.; Zhang, B.; Zhang, Q.; Zhao, H.; Zhao, H.; Zhou, J.; Gabriel, S.B.; Barry, R.; Blumenstiel, B.; Camargo, A.; Defelice, M.; Faggart, M.; Goyette, M.; Gupta, S.; Moore, J.; Nguyen, H.; Onofrio, R.C.; Parkin, M.; Roy; J.; Stahl, E.; Winchester, E.; Ziaugra, L.; Altshuler, D.; Shen, Y.; Yao, Z.; Huang, W.; Chu, X.; He, Y.; Jin, L.; Liu, Y.; Shen, Y.; Sun, W.; Wang, H.; Wang, Y.; Xiong, X.; Xu, L.; Waye, M.M.; Tsui, S.K.; Xue, H.; Wong, J.T.; Galver, L.M.; Fan, J.B.; Gunderson, K.; Murray, S.S.; Oliphant, A.R.; Chee, M.S.; Montpetit, A.; Chagnon, F.; Ferretti, V.; Leboeuf, M.; Olivier, J.F.; Phillips, M.S.; Roumy, S.; Sallée, C.; Verner, A.; Hudson, T.J.; Kwok, P.Y.; Cai, D.; Koboldt, D.C.; Miller, R.D.; Pawlikowska, L.; Taillon-Miller, P.; Xiao, M.; Tsui, L.C.; Mak, W.; Song, Y.Q.; Tam, P.K.; Nakamura, Y.; Kawaguchi, T.; Kitamoto, T.; Morizono, T.; Nagashima, A.; Ohnishi, Y.; Sekine, A.; Tanaka, T.; Tsunoda, T.; Deloukas, P.; Bird, C.P.; Delgado, M.; Dermitzakis, E.T.; Gwilliam, R.; Hunt, S.; Morrison, J.; Powell, D.; Stranger, B.E.; Whittaker, P.; Bentley, D.R.; Daly, M.J.; de Bakker, P.I.; Barrett, J.; Chretien, Y.R.; Maller, J.; McCarroll, S.; Patterson, N.; Pe'er, I.; Price, A.; Purcell, S.; Richter, D.J.; Sabeti, P.; Saxena, R.; Schaffner, S.F.; Sham, P.C.; Varilly, P.; Altshuler, D.; Stein, L.D.; Krishnan, L.; Smith, A.V.; TelloRuiz, M.K.; Thorisson, G.A.; Chakravart,i A.; Chen, P.E.; Cutler, D.J.; Kashuk, C.S.; Lin, S.; Abecasis, G.R.; Guan, W.; Li, Y.; Munro, H.M.; Qin, Z.S.; Thomas, D.J.; McVean, G.; Auton, A.; Bottolo, L.; Cardin, N.; Eyheramendy, S.; Freeman, C.; Marchini, J.; Myers, S.; Spencer, C.; Stephens, M.; Donnelly, P.; Cardon, L.R.; Clarke, G.; Evans, D.M.; Morris, A.P.; Weir, B.S.; Tsunoda, T.; Mullikin, J.C.; Sherry, S.T.; Feolo, M.; Skol, A.; Zhang, H.; Zeng, C.; Zhao, H.; Matsuda, I.; Fukushima, Y.; Macer, D.R.; Suda, E.; Rotimi, C.N.; Adebamowo, C.A.; Ajayi, I.; Aniagwu, T.; Marshall, P.A.; Nkwodimmah, C.; Royal, C.D.; Leppert, M.F.; Dixon, M.; Peiffer, A.; Qiu, R.; Kent, A.; Kato, K.; Niikawa, N.; Adewole, I.F.; Knoppers, B.M.; Foster, M.W.; Clayton, E.W.; Watkin, J.; Gibbs, R.A.; Belmont, J.W.; Muzny, D.; Nazareth, L.; Sodergren, E.; Weinstock, G.M.; Wheeler, D.A.; Yakub, I.; Gabriel, S.B.; Onofrio, R.C.; Richter, D.J.; Ziaugra, L.; Birren, B.W.; Daly, M.J.; Altshuler, D.; Wilson, R.K.; Fulton, L.L.; Rogers, J.; Burton, J.; Carter, N.P.; Clee, C.M.; Griffiths, M.; Jones, M.C.; McLay, K.; Plumb, R.W.; Ross, M.T.; Sims, S.K.; Willey, D.L.; Chen, Z.; Han, H.; Kang, L.; Godbout, M.; Wallenburg, J.C.; L'Archevêque, P.; Bellemare, G.; Saeki, K.; Wang, H.; An, D.; Fu, H.; Li, Q.; Wang, Z.; Wang, R.; Holden, A.L.; Brooks, L.D.; McEwen, J.E.; Guyer, M.S.; Wang, V.O.; Peterson, J.L.; Shi, M.; Spiegel, J.; Sung, L.M.; Zacharia, L.F.; Collins, F.S.; Kennedy, 
K.; Jamieson, R.; Stewart, J. A second generation human haplotype map of over 3.1 million SNPs. Nature, 2007, 449, 851-861.

[41] Butler, J.M.; Budowle B; Gill, P.; Kidd, K.K.; Phillips, C.; Schneider, P.; Vallone, P.M.; Morling, N. Report on ISFG SNP panel discussion. FSI Genet. Suppl. Ser. 1, 2008, 471-472.

[42] Amigo, J.; Phillips, C.; Lareu, M.; Carracedo, A. The SNPforID browser: an online tool for query and display of frequency data from the SNPforID project. Int. J. Legal Med., 2008, 122, 435-440.

[43] Sanchez, J.J.; Phillips, C.; Børsting, C.; Balogh, K.; Bogus, M.; Fondevila, M.; Harrison, C.D.; Musgrave-Brown, E.; Salas, A.; Syndercombe-Court, D.; Schneider, P.M.; Carracedo, A.; Morling, N. A multiplex assay with 52 single nucleotide polymorphisms for human identification. Electrophoresis, 2006, 27, 1713-1724.

[44] Pereira, R.; Fondevila, M.; Phillips, C.; Amorim, A.; Carracedo, A.; Gusmao, L. Genetic characterisation of 52 autosomal SNPs in the Portuguese population. FSI Genet. Suppl. Ser. 1; 2008, 358360 .

[45] Musgrave-Brown, E.; Ballard, D.; Fondevila, M.; Fang, R.; Harrison, C.; Phillips, C.; Prasad, Y.; Sobrino, B.; Thacker, C.; Wiluhn, J.; Carracedo, A.; Schneider, P.; Syndercombe-Court, D. Forensic validation of the Genplex SNP typing system - results of an inter-laboratory study. FSI Genet. Suppl. Ser. 1, 2008, 389-393.
[46] Fondevila, M.; Phillips, C.; Naveran, N.; Cerrezo, M.; Rodriguez, A.; Calvo, R.; Fernandez, L.M.; Carracedo, A.; Lareu, M.V. Challenging DNA : assessment of a range of genotyping approaches for highly degraded forensic samples. FSI Genet. Suppl. Ser. 1, 2008, 26-28.

[47] Gill, P.; Fereday, L.; Morling, N.; Schneider, P.M. The evolution of DNA databases -recommendations for new European STR loci. Forensic Sci. Int., 2006, 156, 242-244.

[48] Gill, P.; Fereday, L.; Morling, N.; Schneider, P.M. New multiplexes for Europe-amendments and clarification of strategic development. Forensic Sci. Int., 2006, 163, 155-157.

[49] Coble, M.D.; Butler, J.M. Characterization of new miniSTR loci to aid analysis of degraded DNA. J. Forensic Sci., 2005, 50, 43-53.

[50] Onofri, V.; Giocoma, I.; Alessandrini, F.; Turchi, C.; Buscemi, L.; Tagliabracci, A. Population data for D10S1248; D14S1434; and D22S1045 miniSTRs loci from the Marches region (Central Italy). FSI Genet. Suppl. Ser. 1, 2008, 353-355.

[51] Peloso, G.; Grignani, P.; Previdere, C. Genetic characterisation of six miniSTR loci in an Italian population sample. FSI Genet. Suppl. Ser. 1, 2008, 356-357.

[52] Butler, J.M.; Hill, C.R.; Decker, A.E.; Kline, M.C.; Vallone, P.M. New autosomal STR loci. FSI Genet. Suppl. Ser. 1, 2008, 95-96.

(C) Gerhard Mertens; Licensee Bentham Open.

This is an open access article licensed under the terms of the Creative Commons Attribution Non-Commercial License (http://creativecommons.org/licenses/by-nc/3.0/) which permits unrestricted, non-commercial use, distribution and reproduction in any medium, provided the work is properly cited. 